\title{
Aspectos que influenciam a criação das Zonas de Especial Interesse Social nos municípios do Estado do Rio de Janeiro
}

Ana Paula Vasconcelos Gonçalves ${ }^{1}$

\begin{abstract}
RESUMO
No Brasil as políticas urbanas e habitacionais não favoreciam as camadas populares, acarretando a segregação habitacional das pessoas mais pobres. Somente a partir da década de 80 que a discussão sobre regulação urbanística, políticas habitacionais inclusivas e gestão democrática das cidades começou a ter mais repercussão. Esta nova mobilização culminou no Estatuto da Cidade que prevê a obrigatoriedade do Plano Diretor e também instrumentos legais para a gestão democrática das cidades, como as Zonas de Especial Interesse Social - ZEIS. No Estado do Rio de Janeiro a partir de 2008 ocorreu um aumento de municípios com Plano Diretor e com áreas definidas como ZEIS, entretanto há cidades que não possuem este instrumento de gestão. Por isso, este trabalho tem como objetivo compreender quais fatores influenciam os municípios do Estado do Rio a incluir em seu Plano Diretor as ZEIS. Tendo em vista que estas zonas estão relacionadas diretamente a habitação, optou-se neste trabalho por verificar quais características dos domicílios e de infraestrutura urbana podem afetar a decisão em questão. Para alcançar tal objetivo foi empregada a regressão logística e os dados utilizados são oriundos do Censo Demográfico de 2010 e da pesquisa do Perfil dos Municípios Brasileiros, ambas realizadas pelo IBGE.
\end{abstract}

PALAVRAS-CHAVE: Plano Diretor, ZEIS, Regressão logística, Segregação.

\section{ABSTRACT}

In Brazil, urban and housing policies were not aimed at the poorest people, leading to housing segregation of the poorest people. Only from the eighties that the discussion of urban regulation, inclusive housing policies and democratic management of cities began to have more impact. This new mobilization culminated in the Statute of the City provides the obligation of the Local Master Plan as well as legal instruments for the democratic management of cities, such as Special Zones of Social Interest - ZEIS. In 2008, the state of Rio de Janeiro there was an increase of municipalities with Plan and areas defined as ZEIS, however there are cities that do not have this management tool. Therefore, this study aims to understand which factors influence the municipalities of Rio State to include in your Plan the ZEIS. Given that these areas are directly related to housing, we chose this work to see which characteristics of households and urban infrastructure that may affect the decision in question. To achieve this goal were used the logistic regression and data were acquired starting from the Census of 2010 and the survey Profile of Brazilian Municipalities, both conducted by IBGE.

\section{Introdução}

No Brasil a população mais pobre sempre teve dificuldade de acesso a moradia e infraestrutura urbana adequada. Este fato foi se agravando no decorrer dos anos com as políticas de embelezamento da cidade, programas de moradia popular que beneficiavam mais a classe média e etc. Desta forma, os indivíduos com menos condições econômicas foram forçados a viver em áreas não urbanizadas, com infraestrutura inadequada e longe do centro da cidade. Estes fatores foram cruciais para intensificar a segregação residencial das pessoas mais pobres no Brasil. 
A segregação pode ser entendida como o agrupamento ou a separação territorial entre determinados grupos socais ou étnicos. Ela pode ser voluntária, quando os indivíduos decidem viver em determinado local por sua própria vontade ou involuntária quando as pessoas são obrigadas a residir em certos locais por forças externas, como o custo da moradia (VILLAÇA, 1998). As causas da segregação são distintas, mas há três tipos de explicações tradicionais que se baseiam em aspectos econômicas, sociais e políticos para explicar o fenômeno em questão (PRÉTECEILLE \& OBERTI, 2016).

Para Préteceille e Oberti (2016) as políticas públicas podem acarretar diretamente a segregação, como o apartheid na África do Sul, ou indiretamente como ações do governo para prover infraestrutura para alguns bairros em detrimento de ouros. Em contrapartida, há medidas que buscam minimizar este problema social, como as políticas habitacionais para integrar o espaço urbano de uma cidade e também a criação de mecanismos legais para a gestão urbana democrática, como legislação de uso do solo, atribuição e permissão para construir, entre outros.

No Brasil, grande parte das políticas públicas não foram eficazes para minimizar as desigualdades socais, entretanto, durante a década de 60 iniciou-se um processo de amadurecimento de um discurso inovador em torno da política urbana. A sociedade civil, os movimentos sociais, pesquisadores e políticos passaram a discutir temas relacionados com a regulação urbanística com o intuito de intervir na formulação de novas políticas públicas, ampliar a participação popular nas decisões locais, visando uma gestão urbana mais democrática e inclusiva.

Estas discussões em torno do planejamento urbano brasileiro proporcionaram a inclusão dos artigos 182 e 183, referente à política urbana, na Constituição Federal de 1988. O Artigo 182 garante desenvolvimento urbano assegurando as funções sociais da cidade e também institui a obrigatoriedade do Plano Diretor nos municípios com mais de 20.000 habitantes. Já o artigo 183 aborda a regularização fundiária (BRASIL, 1988).

No entanto, ainda eram necessários mais avanços neste setor, que mediante a muita luta da sociedade civil, movimentos sociais, pesquisadores e políticos foi aprovado pelo Congresso Nacional em 2001 o Estatuto da Cidade (BRASIL, 2001). Ele instituiu as diretrizes e instrumentos de cumprimento da função social da cidade e da propriedade urbana, da gestão democrática e do direito à cidade (ROLNIK, CYMBALISTA, NAKANO, 2002).

O Estatuto da Cidade prevê instrumentos legais para a gestão democrática das cidades como: direito de superfície, o direito de preempção (de preferência), a outorga onerosa do direito de construir, o estudo de impacto de vizinhança e etc. Esta lei também define a função do Plano Diretor Municipal, reafirmando a obrigatoriedade para as cidades com mais de 20.000 habitantes e aquelas integrantes de regiões metropolitanas e aglomerados urbanos. Também institui outras regras para esta lei, como estar integrado ao plano plurianual, às diretrizes orçamentárias, ao orçamento anual das cidades e a revisão a cada 10 anos e a confecção e revisão dos planos mediante a participação popular.

O Plano Diretor tem como finalidade planejar o desenvolvimento do município de forma includente, visando o desenvolvimento sustentável, a inclusão social e o acesso a todos os serviços e equipamentos urbanos (BRASIL, 2005). Dentre os instrumentos legais que compõem o Plano Diretor os municípios podem incorporar um mecanismo chamado Zona de Especial Interesse Social - ZEIS com o intuito de inserir no zoneamento da cidade uma categoria que permita, mediante um plano específico de urbanização, estabelecer padrões urbanísticos próprios para determinados assentamentos.

É importante ressaltar a existência de municípios que possuem áreas delimitadas como ZEIS e não tem um Plano Diretor instituído, como Carapebus e Aperibé no Estado do 
Rio de Janeiro (IBGE, 2016). Estes casos são pouco frequentes, porque grande parte das cidades incorpora este instrumento de gestão urbana durante a confecção dos seus planos.

As ZEIS podem ser genericamente agrupadas em dois tipos: I) ZEIS de áreas ocupadas, que normalmente são considerados aglomerados subnormais ou assentamento que carecem de regularização fundiária e/ou urbanística. II) ZEIS de áreas vazias, destinadas a produção de habitação de interesse social.

Por isso, ao instituir no Plano Diretor municipal Zonas de Especial Interesse Social permite ao município

\begin{abstract}
(...) reconhecer uma grande parcela da população urbana como cidadãos, e seus locais de moradia - mesmo que informais- como parte da cidade, buscando garantir a recuperação dessas áreas e a melhoria das condições de vida através da instituição de padrões mínimos de urbanização e ocupação do solo. (FERREIRA \& MONTISUKE, 2007. p. 4)
\end{abstract}

Desta forma, as ZEIS são mecanismos legais que podem minimizar a segregação residencial, pois além da questão da regularização da propriedade, o poder público também deverá destinar recursos para melhorar as condições de vida dessa população, oferecendo mais equipamentos e serviços públicos (NUNES \& GIVISIEZ, 2008).

A desigualdade de acesso aos locais de moradia é muito presente nas grandes metrópoles, seja pela autossegregação das pessoas mais ricas em bairros nobres ou em condôminos fechados quanto das pessoas mais pobres, que por falta de escolha, precisam viver onde sua condição financeira permite. Por isso, a confecção do Plano Diretor municipal, com a inclusão de instrumentos de planejamento urbano que possibilitem minimizar estas disparidades, é fundamental para amenizar a segregação existente entres as camadas mais pobres da sociedade.

Há diversas pesquisas que demonstram a presença de segregação residencial no Estado do Rio de Janeiro, principalmente nas grandes cidades (RIBEIRO \& CORREA,2010; VARGAS, 2005; RIBEIRO \& LAGO, 2001; SMOLKA, 1992). Mesmo com o incremento do número de municípios cariocas com Planos Diretores vigentes a inclusão das ZEIS ainda não é grande, por isso este trabalho tem como objetivo compreender quais os fatores quantitativamente mensuráveis influenciam os municípios do Estado do Rio a incluir em seu Plano Diretor as ZEIS. Tendo em vista que estas zonas estão relacionadas diretamente a habitação, optou-se neste trabalho por verificar quais características dos domicílios e de infraestrutura urbana que podem influenciar a decisão em questão.

\title{
2. Materiais e Métodos
}

Para alcançar o objetivo proposto foram utilizadas as informações oriundas da pesquisa sobre o Perfil dos Municípios Brasileiros (IBGE, 2016), de onde foram obtidos os dados referente a legislação urbana dos municípios do Estado do Rio de Janeiro. Já as informações sobre a infraestrutura urbana e os domicílios do Estado foram extraídas do Censo Demográfico de 2010, realizado pelo IBGE. As variáveis inicialmente pré-selecionadas foram:

- Plano Diretor;

- ZEIS;

- Domicílios com esgoto sanitário; 
- Domicílios com coleta de lixo;

- Domicílios com água encanada;

- Domicílios com pavimentação no entorno;

- Domicílios com iluminação pública no entorno;

- Domicílios Próprios;

- Domicílios Alugados;

- Domicílios com rendimento nominal mensal domiciliar de até 1 salário mínimo.

Os dados sobre relacionados com o Plano Diretor e as ZEIS extraídos do Perfil dos Municípios Brasileiros somente indicam se a cidade tem confeccionado o Plano Diretor e quais instrumentos de gestão estão inclusos, dentre eles as ZEIS. Não há a informação sobre qual tipo de ZEIS foi implementada, se de áreas ocupadas ou vazias.

É importante destacar, que devido as limitações nos dados disponíveis as informações são de períodos distintos, entretanto foram escolhidas as fontes mais confiáveis e com as datas de coletas mais próximas das informações sobre o Plano Diretor e as ZEIS, que será a varável dependente do modelo.

Outro aspecto que merece ser enfatizado, está relacionado com a escolha da metodologia empregada. Este estudo é uma tentativa de mensurar, a partir dos dados quantitativos disponíveis, quais fatores podem influenciar a criação das ZEIS nos municípios, por isso as variáveis relacionadas com questões sociopolíticas, com a história local e outros aspectos qualitativas não são utilizados neste artigo.

$\mathrm{O}$ modelo escolhido para entender quais fatores urbanos e domiciliares tendem a influenciar os municípios a criarem ZEIS em seu território foi a regressão logística. Esta técnica consiste em uma regressão múltipla cuja variável dependente do modelo é categórica dicotômica e as variáveis independentes podem ser contínuas ou categóricas (FIELD, 2009).

A variável dependente deste artigo indica se município tem alguma área delimitada como ZEIS. Se tiver tal atributo assume o valor um, caso contrário recebe o valor zero. Neste caso a variável é categórica dicotômica, porque ela apresenta somente dois valores que não estabelecem uma ordem de grandeza entre si.

A regressão logística também conhecida como "Logit" pertence à família exponencial, tem uma distribuição de probabilidade de Bernouli ou binomial e conforme destaca Dobson (2002), o modelo logístico para o caso geral pode ser escrito como:

$$
\ln \left(\frac{\pi_{i}}{1-\pi_{i}}\right)=x_{i}^{T} \beta
$$

\footnotetext{
ONDE:

$\boldsymbol{\pi} \boldsymbol{i}$ corresponde a probabilidade de sucesso da i-ésima observação;

$\boldsymbol{x} \boldsymbol{i}$ corresponde ao vetor de variáveis regressoras; e

$\boldsymbol{\beta}$ corresponde ao vetor de parâmetros dos coeficientes a serem estimados.
} 
Esta é a representação mais comum, entretanto existem duas outras representações: a escala de probabilidade e a escala das chances (odds). A escala de probabilidade é a forma estrutural do modelo logístico, onde os termos do modelo são escritos em função da probabilidade de sucesso, conforme é apresentado abaixo

$$
\pi_{i}=\left(\frac{e^{x_{i}^{T} \beta}}{1+e^{x_{i}^{T} \beta}}\right)
$$

Esta escala é útil quando se deseja estimar a probabilidade de sucesso dada outras variáveis regressoras, para avaliar certo fenômeno, ou seja, quando alguns valores das variáveis regressoras são fixadas em valores predeterminados e os demais são considerados constantes.

A segunda forma de representação do modelo logístico é através da escala de odds, que relaciona a probabilidade de sucesso de determinado evento com a probabilidade de fracasso. Através desta forma estrutural é possível calcular a odds, dada por:

$$
\frac{\pi_{i}}{1-\pi_{i}}=e^{x_{i}^{T} \beta}
$$

Neste trabalho será utilizada a segunda forma de representação descrita - o odd para relacionar a probabilidade de ter ZEIS em um dado município com a probabilidade oposta, ou seja, o município não ter implementado o instrumento urbano que está sendo discutido neste artigo.

\section{Discussão dos resultados}

De acordo com o artigo 50 do Estatuto da Cidade (2001), 2008 foi o prazo limite para as cidades se ajustarem em relação a obrigatoriedade do Plano Diretor. Por este motivo o número de municípios com esta lei aumentou juntamente com o crescimento da implementação dos instrumentos legais para gestão das cidades. No Estado do Rio de Janeiro esta evolução pode ser observada através do Gráfico 1. Em 2005, somente 27 municípios do Estado tinham implementado esta lei e no ano de 2008 este número saltou para 70 cidades, um acréscimo de aproximadamente $160 \%$.

Após o ano de 2009 a quantidade de cidades com o Plano Diretor se manteve estável, entorno de $75 \%$ dos municípios do Estado do Rio de Janeiro. As demais localidades provavelmente não se enquadram no perfil de obrigatoriedade do Plano Diretor ${ }^{2}$, por isso optaram por não criar esta lei.

\section{Gráfico 1 - Quantidade de municípios do Estado do Rio de Janeiro com Plano Diretor}

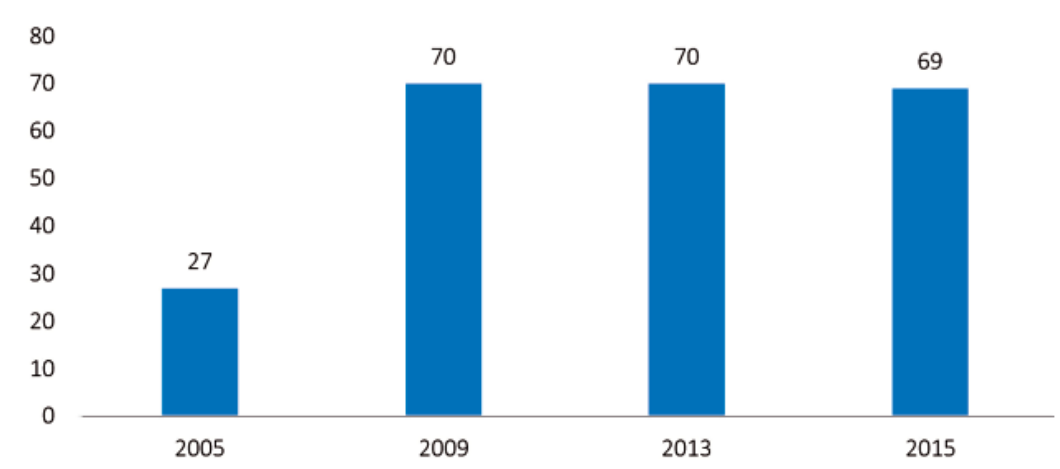

Fonte: IBGE, 2016

2 O Plano Diretor é obrigatório para as cidades com mais de 20.000 habitantes e aquelas integrantes de regiões metropolitanas e aglomerados urbanos (BRASIL, 2005). 
Nas cidades que possuem Plano Diretor, existe a possibilidade de incorporar uma série de instrumentos de gestão urbana na lei em questão, tal como as ZEIS. No Estado do Rio de Janeiro, em 2005, somente 23 cidades possuíam áreas instituídas como ZEIS em seu território. No ano de 2009 passou para 58 municípios, um incremento de aproximadamente $152 \%$ e em 2013 o aumento foi de 15\%. Em 2015 quantidade de locais com ZEIS se manteve estável.

Nos três anos da pesquisa sobre a legislação de gestão urbana, realizada pelo IBGE, os dados demonstraram que sempre existiu mais cidades com Planos Diretores do que ZEIS, entretanto a diferença não é muito grande. Nos anos de 2005, 2013 e 2015 esta diferença não ultrapassou 5 unidades. Somente no ano de 2008 ocorreu uma diferença um pouco maior, pois eram 67 cidades com Plano Diretor e 58 com ZEIS criadas, uma diferença de 18 municípios.

\section{Gráfico 2 - Quantidade de municípios do Estado do Rio de Janeiro com ZEIS}

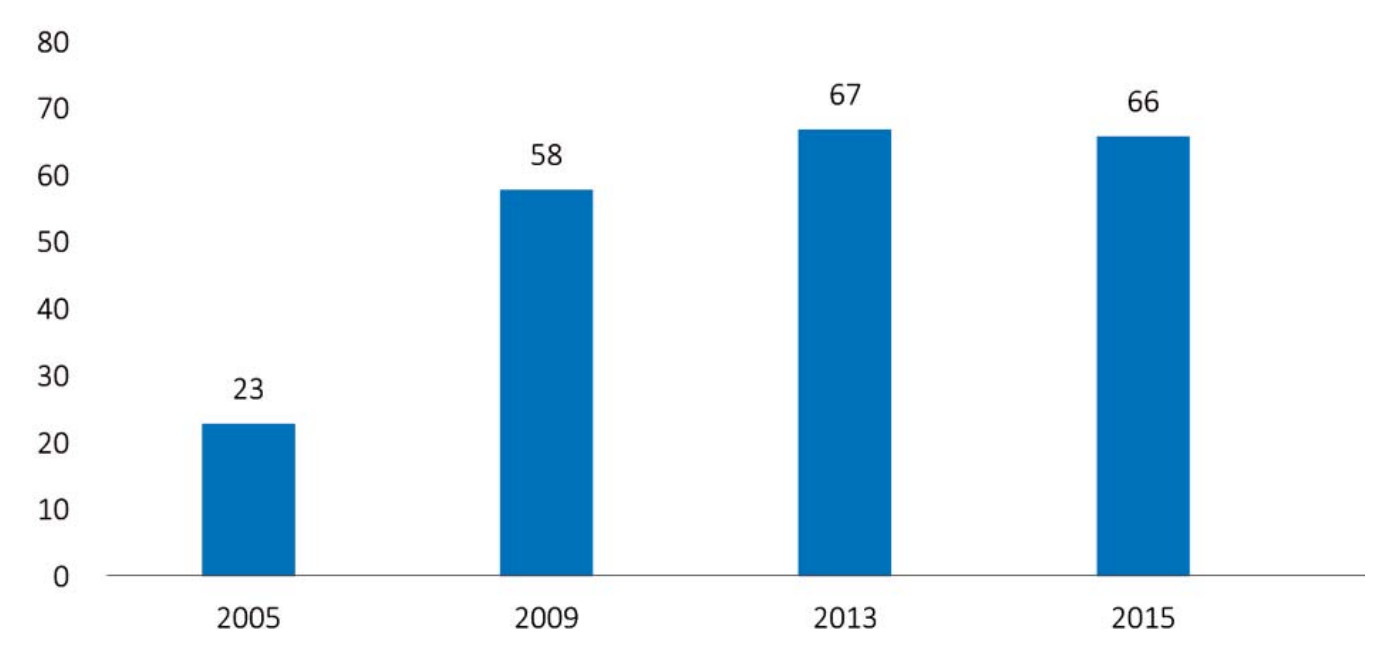

Fonte: IBGE, 2016

Com o intuito de visualizar os locais que em 2015 possuíam ou não Zonas de Especial Interesse Social e como elas estavam distribuídas espacialmente foi confeccionado o Mapa 1. A partir desta figura verificou-se a presença de alguns clusters entre os municípios que não tem áreas delimitadas como ZEIS em seus territórios. Guapimirim é a única cidade que compõe a região metropolitana e não tem áreas de ZEIS instituídas, assim como Mendes, Miguel Pereira e Engenheiro Paulo de Frontin que estão localizadas à oeste da região metropolitana do Rio de Janeiro.

No centro do Estado há um agrupamento de dez cidades que também não tem este instrumento. E ao norte existem mais duas outras, na qual alguns municípios fazem fronteira com os Estados de Minas Gerais e Espírito Santo. Itaperuna separa um cluster do outro, pois abaixo dela estão localizados seis municípios sem ZEIS e acima quatro.

As duas únicas localidades que não possuem ZEIS e estão isoladas, ou seja, não tem nenhuma cidade vizinha com esta mesma características são Guapimirim e Comendador Levy Gasparian.

A análise exploratória da variável Plano Diretor e da variável dependente do ZEIS, demonstra que no Estado do Rio de Janeiro não são todas as cidades que possuem Plano Diretor e Zonas de Especial Interesse Social. Contudo, a 
obrigatoriedade do Plano Diretor em 2008 possivelmente influenciou o aumento das cidades com áreas de ZEIS. Em relação à distribuição espacial dos municípios sem o instrumento de gestão urbana estudado, nota-se elas estão agrupadas espacialmente, principalmente, na área central e no norte do Estado.

\section{Mapa 1 - Municípios com ZEIS em 2015}

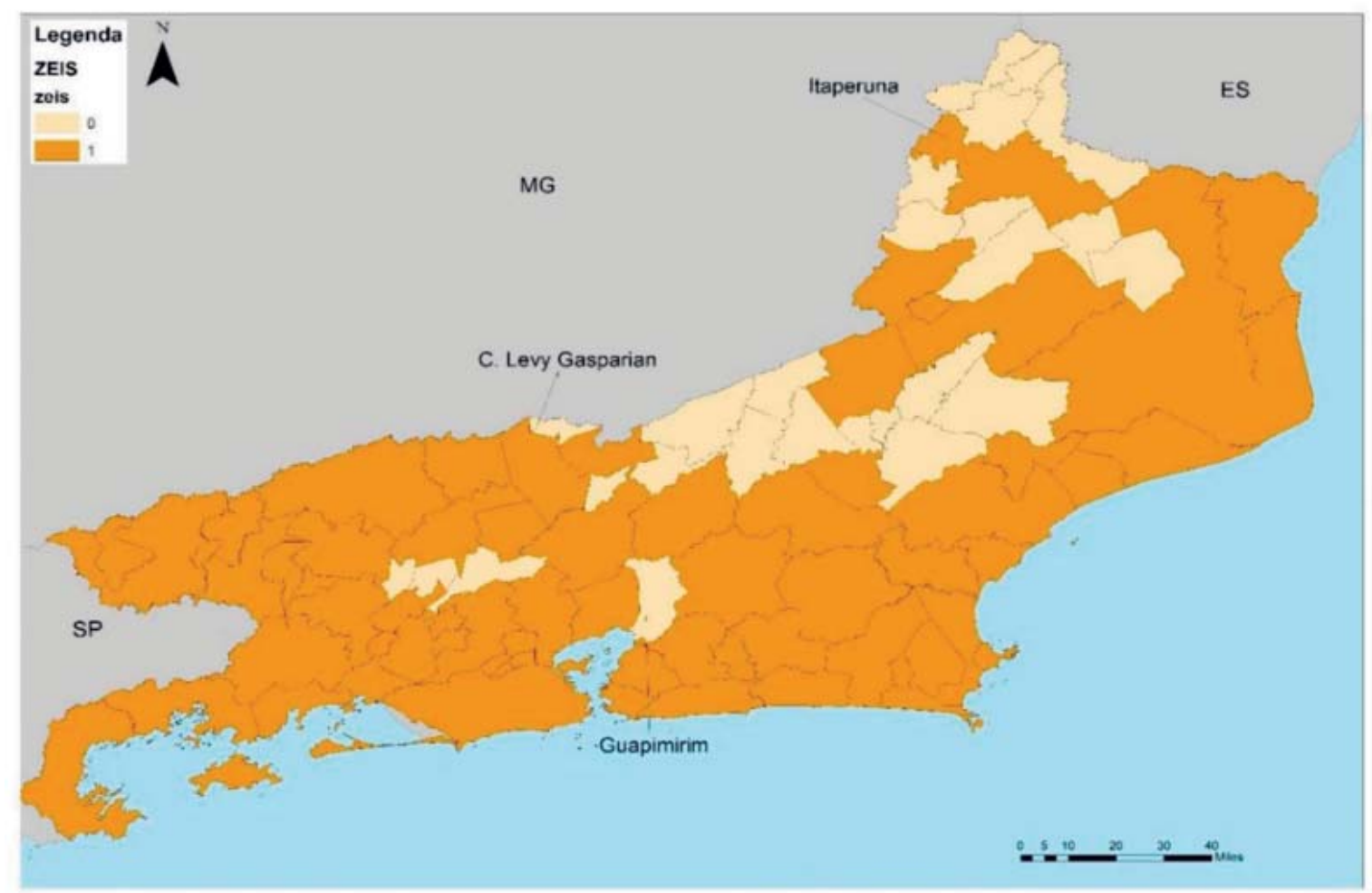

Fonte: IBGE, 2016

Para continuar a análise exploratória dos dados, que serão utilizados na regressão logística, foi construído o Quadro 1 que contém as estatísticas descritas das variáveis pré-selecionadas como dependente do modelo.

Os valores descritos como mínimo das informações são pequenos e os máximos são muito altos, contribuindo para uma grande amplitude. Isto ocorre, porque os municípios do Estado do Rio de Janeiro possuem tamanho, população e quantidade de domicílios muito distintos uns dos outros. O desvio padrão e a variância das variáveis são altos indicando grande variabilidade em relação à média.

As variáveis iluminação e pavimentação do entorno dos domicílios apresentam estatísticas descritivas similares, sendo um indício de que um domicílio que possui pavimentação no entorno, possivelmente também tem iluminação.

Quadro 1 - Estatísticas descritivas das variáveis pré-selecionadas

\begin{tabular}{|c|c|c|c|c|c|}
\hline VARIÁVEIS & MÍNIMO & MÁXIMO & MÉDIA & DESVIO PADRÃO & VARIÂNCIA \\
\hline Esgoto & 200 & 1949962 & 43648,93 & 205536,066 & 42245074322,567 \\
\hline Alugado & 230 & 478663 & 11039,48 & 50245,091 & 2524569211,373 \\
\hline Próprio & 1169 & 1567765 & 42674,48 & 166973,750 & 27880233165,022 \\
\hline Agua & 1084 & 2111537 & 48198,66 & 222007,794 & 49287460506,666 \\
\hline
\end{tabular}




\begin{tabular}{|c|c|c|c|c|c|}
\hline VARIÁVEIS & MÍNIMO & MÁXIMO & MÉDIA & DESVIO PADRÃO & VARIÂNCIA \\
\hline Lixo & 1583 & 2128390 & 55203,93 & 225230,885 & 50728951614,677 \\
\hline Iluminação & 1021 & 1883636 & 51694,83 & 200950,035 & 40380916750,783 \\
\hline Pavimentação & 1021 & 1883636 & 51694,83 & 200950,035 & 40380916750,783 \\
\hline sm1 & 374 & 210759 & 7704,97 & 23327,947 & 544193134,559 \\
\hline
\end{tabular}

Todas as informações pré-selecionadas inicialmente foram inseridas no modelo de regressão logística, tendo como variável dependente ter ou não ZEIS no município. Entretanto, nem todos os dados obtiverem resultados satisfatórios no modelo. Algumas variáveis não foram significantes, outras com a razão de chances praticamente nula. Desta forma, a regressão foi realizada diversas vezes e a interação das variáveis foi testada até alcançar o melhor ajuste do modelo.

Os dados referentes aos domicílios próprios, domicílios com pavimentação no entorno e domicílios com rendimento nominal mensal domiciliar de até 1 salário mínimo obtiverem melhores resultados, pois todas as variáveis são significantes. Vale ressaltar que pavimentação e iluminação estavam fortemente correlacionadas. Isto indica que provavelmente onde existe pavimentação tem iluminação, assim como as outras variáveis do entorno que foram coletadas pelo Censo de 2010.

Neste modelo o pseudo $\mathrm{R}^{2}$, que tem como objetivo mensurar a proporção da variabilidade explicada pelo modelo, foi de 0,5343 considerado um valor bom para dados sociais.

No Quadro 2 estão os coeficientes da regressão logística que demonstram o erro padrão, a significância estatística das variáveis dependentes e o valor estimado para cada informação. A partir do valor estimado nota-se que os domicílios próprios influenciam positivamente a chance de ter ZEIS nos municípios do Estado do Rio de Janeiro. Em contrapartida pavimentação no entorno dos domicílios e o rendimento nominal mensal de até um salário mínimo tem impacto negativo, ou seja, diminui as chances de um município ter implementado este instrumento legal.

Quadro 2 - Coeficientes da Regressão Logística

\begin{tabular}{|c|c|c|c|c|}
\cline { 2 - 5 } \multicolumn{1}{c|}{} & VALOR ESTIMADO & ERRO PADRÃO & Z VALOR & $\operatorname{Pr}(>|z|)$ \\
\hline INTERCEPTO & -22.991 .809 & 0.8358297 & -2.751 & 0.00595 ** \\
\hline PRÓPRIO & 0.0035741 & 0.0012577 & 2.842 & $0.00449 * *$ \\
\hline PAVIMENTAÇÃO & -0.0015766 & 0.0006996 & -2.254 & $0.02422{ }^{*}$ \\
\hline 1 SM & -0.0042335 & 0.0015435 & -2.743 & $0.00609 *$ \\
\hline
\end{tabular}

Os valores estimados podem ser interpretados como o logaritmo da taxa de sucesso versus a taxa de fracasso (POWERS \& XIE, 2008), então é preciso transformá-los em probabilidades calculando seus logaritmos. Após esta operação se obtém a razão de chance para cada variável independente do modelo, que está descrito no Quadro 3. Como a unidade utilizada neste trabalho é o domicílio, fica difícil visualizar a razão de chance para cada mudança de uma unidade, pois os valores são muito pequenos, por isso também foi calculada esta probabilidade para cada cem unidades.

Para cada domicílio próprio a chance de ter áreas de ZEIS instituídas nas cidades do Estado do Rio de Janeiro aumenta em 0,003\%, parece pouco mas não é, porque 
em todo Estado há 5.243.029 domicílios. Se a razão de chances for calculada para 100 residências ela salta para $35 \%$. Portanto, quanto mais domicílios próprios nas cidades maiores as chances de ter Zonas de Especial Interesse Social. Esta influência positiva pode estar relacionada principalmente com as ZEIS destinadas para regularização fundiária, que são espaços já ocupados, cujos residentes possuem imóveis oriundos de posse ou que estão irregulares por outros motivos. Também é importante destacar, que mesmo as ZEIS vazias, serão destinadas para habitação social.

Em relação a pavimentação do entorno dos domicílios, a razão de chances para uma unidade é de - 0,001, indicando que para cada moradia com esta característica a chance de ter ZEIS no território diminui. 0,001. No caso de cem domicílios, a queda na probabilidade é de aproximadamente $15 \%$. O aumento da pavimentação no entorno diminuiu as chances das cidades terem ZEIS, porque este atributo é positivo para os bairros. Este é um indicativo da existência de outras características relacionadas à infraestrutura como iluminação, bueiros na rua e meio fio. Por isso, os lugares cujos domicílios apresentam condições mais adequadas em seu entorno, estão propensos a possuir melhores condições de infraestrutura, logo a necessidade de regularização fundiária ou de ter um área delimitada como ZEIS tende a diminuir, quando comparadas aos locais sem estas características.

A variável rendimento nominal mensal domiciliar de até 1 salário mínimo também tem influência negativa na razão de chances de ter ZEIS nos municípios. Para cada domicílio com este atributo a chance cai em $0,004 \%$ e para cada cem domicílios a chance diminui em aproximadamente $42 \%$. Esta variável interfere negativamente, ou seja, quanto mais domicílios com rendimento médio, para cada integrante, de até um salário mínimo, tende a diminuir as chances de ZEIS nos locais. Esta situação ocorre, porque estas residências possuem ao menos condições financeiras mínimas, diferente dos lugares com residências sem rendimentos. Este fato reflete na estrutura domiciliar, no bairro de moradia, e etc.

Quadro 3 - Razão de Chances

\begin{tabular}{|c|c|c|c|}
\hline VARIÁVEIS & $\begin{array}{c}\text { RAZÃO DE CHANCE } \\
\text { (ODD RATIO) }\end{array}$ & $\begin{array}{c}\text { RAZÃO DE CHANCE } \\
\text { PARA UMA UNIDADE }\end{array}$ & $\begin{array}{c}\text { RAZÃO DE CHANCE } \\
\text { PARA CEM UNIDADES }\end{array}$ \\
\hline Próprio & 1,003581 & 0,003581 & 0,3581 \\
\hline Pavimentação & 0,9984247 & $-0,0015753$ & $-0,15753$ \\
\hline 1 SM & 0,9957754 & $-0,0042246$ & $-0,42246$ \\
\hline
\end{tabular}

A partir da análise das informações obtidas pelo modelo de regressão logística foi possível verificar que as condições dos domicílios, renda domiciliar e infraestrutura urbana influenciam a probabilidade de um município do Estado do Rio de Janeiro ter Zonas de Interesse Social ou não. Entretanto é preciso analisar os resíduos do modelo para verificar a adequação do mesmo (HAIR Et Al, 2009).

Os Gráficos 3 e 4 apresentam a distribuição e o QQ-Plot dos resíduos. Em ambos os gráficos há um outlier que é a cidade do Rio de Janeiro. Este fato pode ocorrer por conta de suas características muito discrepantes dos demais municípios, como sua elevada população e consequentemente seus domicílios, porém optou-se por mantê-lo no modelo devido sua importância para o Estado.

O Gráfico 3 avalia a normalidade dos resíduos. Nele nota-se que há alguns pontos discrepantes na cauda direita e no centro da distribuição dos resíduos além do outlier, mas em geral os dados estão normalmente distribuídos. No Gráfico 4, os resíduos não estão aleatoriamente distribuídos, sendo possível observar uma tendência em torno do zero. 

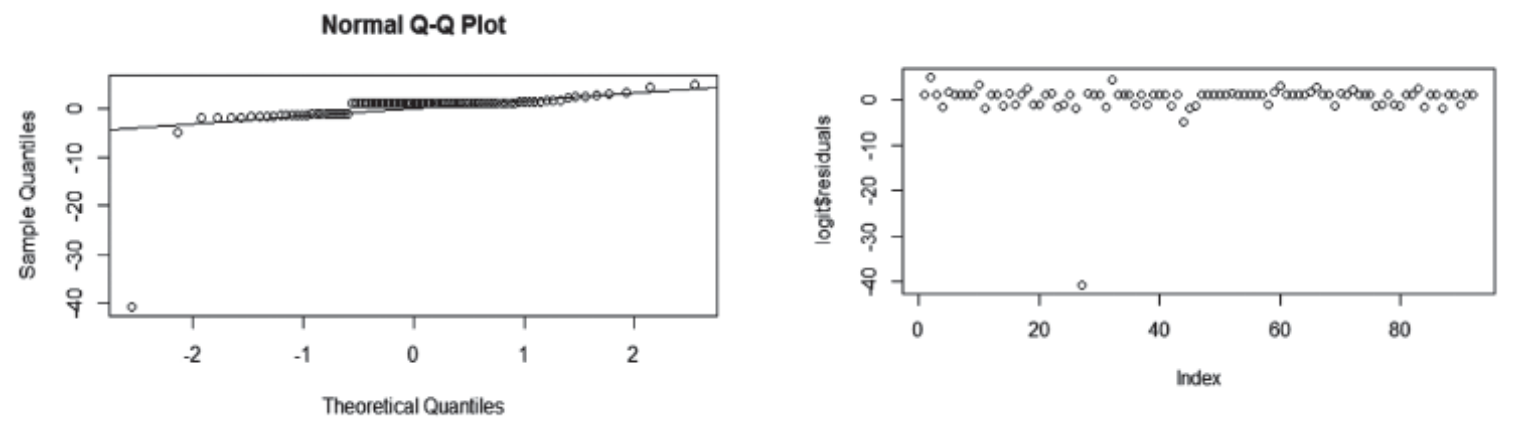

Como há presença de clusters das cidades que não possuem ZEIS em seu território também é preciso verificar a correlação espacial dos resíduos (ALMEIDA, 2012). Para isto foi calculado o Índice de Moran que mede a autocorrelação espacial a partir do produto dos desvios em relação à média. É um índice de medida global de autocorrelação, pois indica o grau de associação espacial presente no conjunto de dados (ANSELIN, 1995).

No Gráfico 5 estão o Índice de Moram e seu diagrama de espalhamento, que permite analisar o comportamento da variabilidade espacial dos dados. O valor do índice é de aproximadamente 0,1 indicando que a correlação espacial dos resíduos é muito baixa. Este fato indica que não é preciso realizar uma regressão espacial para melhorar o modelo realizado.

O diagrama de espalhamento de $\operatorname{moran}^{3}$ indica que grande parte dos resíduos não tem correlação espacial, pois estão bem próximos do zero. A maior concentração dos dados que apresenta correlação está no quadrante Q2 que se caracteriza por valores negativos e médias negativas.

\section{Gráfico 5 - Espalhamento de Moran}

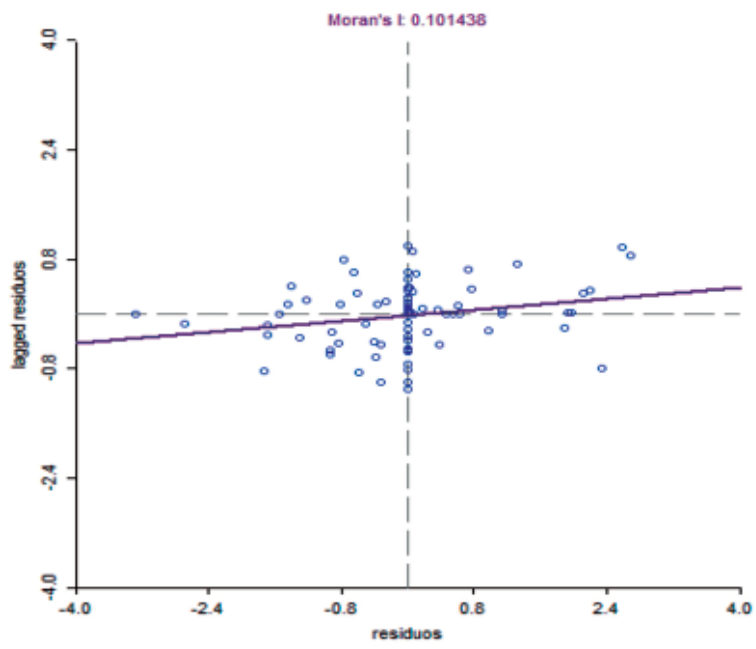

A análise dos resíduos indica que não há correlação espacial, e a presença do outlier afeta a regressão logística realizada. Contudo o ajuste do modelo ainda é adequado para compreender os fatores domiciliares e de infraestrutura urbana que tendem a influenciar na chance de um município do Estado do Rio de Janeiro criar áreas definidas como Zonas de Interesse social.

3 Para compreender melhor o gráfico de espalhamento de moran ver: Santos Et Al (2007), Neves Et Al e Anselin (1995). 


\section{Considerações Finais}

O avanço da implementação dos Planos Diretores nos municípios do Estado do Rio de Janeiro foi perceptível com a obrigatoriedade desta lei a partir de 2008, este fato também influenciou a implementação das Zonas de Especial Interesse Social. Contudo é importante ressaltar que nem todas as cidades que tem Plano Diretor possuem ZEIS implementadas em seus territórios, por isso a quantidade de cidades com ZEIS ainda é menor que o número de municípios com o Plano Diretor.

Como uma grande quantidade de municípios colocou em seu Plano Diretor as ZEIS, isto tende a indicar que o poder público local e a sociedade civil acreditam neste instrumento de gestão, pois ele poderia ser pouco utilizado nos planos diretores e não foi isto o observado na análise exploratória. Certamente as pessoas envolvidas na confecção e revisão do Plano Diretor nos municípios do Estado do Rio de Janeiro acreditam que as ZEIS são úteis, em alguma medida para as cidades, e que pode ser uma forma de minimizar as desigualdades habitacionais e ampliar a equidade no acesso à cidade.

O aumento da previsão legal das ZEIS como mecanismo de gestão urbana tende a maximizar o acesso a moradia digna para as pessoas mais pobres, porque dependendo das ZEIS instituídas serão construídas novas habitações destinadas a moradia social ou serão realizado projetos visando a regularização fundiária das moradias já existentes. Desta forma a segregação residencial pode a ser minimizada nas cidades que possuem este mecanismo instituído.

No caso do Estado do Rio de Janeiro, não são todos os municípios que possuem Plano Diretor, nem ZEIS como instrumento de gestão urbana. As cidades que não tem as ZEIS não estão na região metropolitana, com exceção de Guapimirim. Elas estão localizadas no centro e ao norte do Estado. A presença de clusters tende a indicar a influência que uma cidade pode exercer em sua vizinha no que tange a confecção de suas leis urbanas.

Este trabalho conseguiu mensurar quais são as principais características quantitativas relacionadas com as condições domiciliares que estão fortemente relacionadas com a criação das ZEIS no Estado do Rio de Janeiro, como os domicílios próprios, domicílios com rendimento nominal mensal domiciliar de até 1 salário mínimo e domicílios com pavimentação no entorno. Estas variáveis apresentaram significância satisfatória no modelo, demonstrando grande probabilidade destas características explicarem melhor o tema em questão que as demais pré-selecionadas.

É importante ressaltar que nesta pesquisa só foi possível aferir o que poderia influenciar na criação das ZEIS e não analisar sua efetividade em relação à diminuição das desigualdades. Devido a escolha metodologia, também não foi possível mensurar atributos qualitativos que estão relacionados com os Planos Diretores e as ZEIS. Diante disto, como sugestão para trabalhos posteriores seria interessante fazer uma pesquisa qualitativa para compreender outros fatores que influenciam um município a criar as ZEIS e verificar se os locais com ZEIS instituídas têm diminuído as desigualdades sociais e espaciais, principalmente no que tange o acesso a moradia adequada e a infraestrutura urbana. 


\section{Referências bibliográficas}

ALMEIDA, E. S. Econometria Espacial Aplicada. Campinas, SP, 2012, Editora Alínea.

ANSELIN, L. Local indicator of spatial association - LISA. In: Geografical Analysis, 1995. p. 91-115.

BRASIL. Constituição da República Federativa do Brasil. Brasília, DF: Senado Federal: Centro Gráfico, 1988. 292 p.

BRASIL. Estatuto da Cidade. Lei n. 10.257 de 10 de julho de 2001. Estabelece diretrizes gerais da política urbana e dá outras providências. Diário Oficial da União, Brasília, 11 jul. 2001 a.

BRASIL, Ministério das Cidades. Plano Diretor Participativo: Guia para Elaboração pelos municípios e cidadãos. Brasília: Ministério das Cidades, Confea, 2005.

DOBSON, A. J. An Introduction to Statistical Modelling. London: Chapman and Hall, $2^{\mathrm{a}}$ edição 2002. 264 p.

FERREIRA,J. S. W; MOTISUKE, D. A efetividade da implantação de Zonas Especiais de Interesse Social no quadro habitacional brasileiro: uma avaliação inicial. In BUENO, Laura Machado de Mello; CYMBALISTA, Renato (Orgs.). Planos Diretores Municipais: PUCCAMP, 2007.

Field, A. Descobrindo a estatística usando o SPSS, $2^{\mathrm{a}}$ ed., Porto Alegre: Artmed, 2009.

IBGE. Sinopse do Censo demográfico 2010. Rio de Janeiro, 2011.

IBGE. Perfil dos Municípios Brasileiros 2015. Rio de Janeiro, 2016.

HAIR, J.F.; BLACK, W.C.; BABIN, B.J.; ANDERSON, R.E. \& TATHAM, R.L. Análise multivariada de dados. 6.ed. Porto Alegre, Bookman, 2009. 688p.

NEVES, M.; RAMOS, F.; CAMARGO, E.; CÂMARA, G.; MONTEIRO, A. Análise exploratória de dados sócio-econômicos de São Paulo. [S.I.:s.n]

NUNES, L. S.; GIVISIEZ, G. H. N.. As áreas de especial interesse social no município de Campos dos Goytacazes: uma análise quantitativa. In: XVI Encontro Nacional de Estudos Populacionais, 2008, Caxambu, Minas Gerais. Anais.... Caxambu, Minas Gerais: ABEP, 2008. v. 1. p. 1-19.

OBERTI, M; PRÉTECEILLE, E. La ségrégation urbaine. La Découverte, coll. Repères, sociologie. Paris, 2016, 128 p.,

POWERS, D.A; XIE, Y.. Statistical methods for categorical data analysis. Emerald Group Publishing, 2008.

RIBEIRO, L.C.Q. CORREA, F.S. As Cores das Fronteiras Urbanas. Segregação residencial e Desigualdades "Raciais" na região Metropolitana do Rio de Janeiro, In: Olhares sobre a Metrópole do Rio de Janeiro - economia sociedade e território. Rio de Janeiro: Letra Capital Editora, 2010.

RIBEIRO, L. C. Q.; LAGO, L. C. A Oposição Favela -Bairro no Espaço Social do Rio de Janeiro. São Paulo Perspec., São Paulo, v. 15, n. 1, p. 144-154, Jan. 2001.

ROLNIK, R.; CYMBALISTA, R.; NAKANO, Kazuo. Solo Urbano e habitação de interesse social: A questão fundiária na política habitacional e urbana do 
país. 39p. 2002.

SANTOS, M.; STRAUCH, J.; ALMEIDA, C. Comparação de ferramentas de sistemas de informações geográficas para análise exploratória de dados de área. In: XXIII Congresso Brasileiro de Cartografia, I Congresso Brasileiro de Geoprocessamento, 2007, Rio de Janeiro.

SMOLKA, M. O. Mobilidade intra-urbana no Rio de Janeiro: da estratificação social à segregação residencial no espaço. In: VII ENCONTRO NACIONAL DE ESTUDOS POPULACIONAIS DA ABEP. Anais do VIII Encontro de Estudos Populacionais da ABEP. Brasília, v. 3, p. 331-350, 1992 .

VARGAS, J. H. C. Apartheid brasileiro: raça e segregação residencial no Rio de Janeiro. Rev. Antropol., São Paulo, v. 48, n. 1, p. 75-131, June 2005.

VILLAÇA, F. Espaço intra-urbano no Brasil. São Paulo: Studio Nobel, 1998. 